\title{
CARMEn SAggiomo, Gide face à Dostoïevski. Par delà le mariage du Bien et du Mal
}

\section{Riccardo Benedettini}

\section{OpenEdition}

\section{Journals}

\section{Edizione digitale}

URL: http://journals.openedition.org/studifrancesi/16006

DOI: 10.4000/studifrancesi. 16006

ISSN: 2427-5856

\section{Editore}

Rosenberg \& Sellier

\section{Edizione cartacea}

Data di pubblicazione: 1 décembre 2018

Paginazione: $547-548$

ISSN: 0039-2944

\section{Notizia bibliografica digitale}

Riccardo Benedettini, "CARmen SAggiomo, Gide face à Dostoïevski. Par delà le mariage du Bien et du Mal», Studi Francesi [Online], 186 (LXII | III) | 2018, online dal 01 janvier 2019, consultato il 06 janvier 2021. URL: http://journals.openedition.org/studifrancesi/16006 ; DOI: https://doi.org/10.4000/studifrancesi. 16006

Questo documento è stato generato automaticamente il 6 janvier 2021.

\section{(c) (i)}

Studi Francesi è distribuita con Licenza Creative Commons Attribuzione - Non commerciale - Non opere derivate 4.0 Internazionale. 


\title{
CARMEN SAGGIOMO, Gide face à Dostoïevski. Par delà le mariage du Bien et du Mal
}

\author{
Riccardo Benedettini
}

\section{NOTIZIA}

CARMEN SAGGIOMO, Gide face à Dostoïevski. Par delà le mariage du Bien et du Mal, préface de Pierre Masson, Publications de l'Association des Amis d'André Gide, 2018, 200 pp.

1 A tre anni di distanza da La fortuna delle "Caves du Vatican" di André Gide (Aracne, 2015), Carmen SAGGIOMO, docente e organizzatrice di convegni su Gide presso l'Università degli Studi della Campania, ci dà questa monografia che, ripercorrendo l'interesse dello scrittore francese per l'opera di Dostoevskij, offre uno specimen degli estesi e frementi interessi gidiani. Se Dostoevskij esorcizza i propri demoni incarnandoli nell'opera romanzesca, era stato notato da Girard, Carmen Saggiomo ha il merito di presentarci uno studio in cui si può riconoscere un filo unitario proprio nel rapporto "lacerante" e "paradossale" tra "umiltà" e "umiliazione", una duplicità che è forse inerente al carattere di Gide stesso, come anche Pierre Masson sottolinea nella «Préface» (pp. 5-9): «[Gide] trouve en Dostoïevski un explorateur exemplaire des régions obscures de l'homme, plutôt qu'en Freud qui prétend venir à bout de cette obscurité [pensiamo all'interpretazione del fenomeno totemico in Totem e tabù]» (p. 7). Articolando il proprio studio in otto capitoli («Gide "le continuateur clairvoyant" de Dostoïevski», pp. 11-23; «Perspectives et méthodes de Gide», pp. 25-40; «Perspectives et méthodes de Dostoïevski», pp.41-52; «Les paradoxes de la sincérité», pp. 53-71; «La question de l'existence de Dieu et les dilemmes du nihilisme», pp. 73-80; «La question de l'art et la présence du mal», pp. 81-118; «Gide après Dostoïevski», pp.119-183; «Le sens d'un voyage», pp.185-198), Carmen Saggiomo riconosce come, nell'essere umano di "Dostoevskij interpretato da Gide", sia doveroso distinguere tra regione intellettuale, 
regione delle passioni e regione dell'anima profonda. E così "Gide interprete di Dostoevskij" - nella sua sesta conferenza sullo scrittore russo, cita l'A., Gide paragona la propria lecture dell'opera dostoevskijana all'andirivieni delle colorate abeilles di Montaigne - si trova di fronte a un quadro antropologico preciso, fatto di ragioni comuni: l'amore per la letteratura, l'interesse per l'uomo della strada, la curiosità per i fatti di cronaca, per la erotia della vita criminale nonché per lo studio delle riforme giudiziarie in corso, tutte sollecitazioni "pour faire ressurgir ses propres mondes en pleine lumière» (p. 120). Di particolare rilievo la nuova interpretazione che Carmen Saggiomo, con una messa a punto chiara e il più possibile completa degli studi ormai classici e di quelli di questi ultimi anni, dà della continuità tra il nichilismo di Dostoevskij e di Nietzsche e la concezione dell'atto gratuito di Gide, giungendo ad un'idea di «antihumanisme littéraire» (p.187) in cui l'umano comprende in sé cose, fatti e rapporti lontani (il Bene e il Male, presenti già nel sottotitolo del volume) perché essi rappresentano un'infinita possibilità di apertura dell'Io, non solo letterario. Svidrigailov di Delitto e castigo si figurava l'eternità come uno stanzino annerito dal fumo, con ragnatele in tutti i cantucci: Carmen Saggiomo sottolinea come gli insoumis di Gide siano anch'essi, spesso, portatori di una eternità di dannazione morale in cui il male è un «facteur inévitable» (p. 109). 